\title{
39 USING SOCIAL CAPITAL AS A CONCEPTUAL FRAMEWORK FOR PROFESSIONAL VIRTUAL COMMUNITIES FORMALIZATION
}

\author{
Servane Crave ${ }^{1,2}$, Thierry Bouron ${ }^{1}$, Sylvie Ladame ${ }^{1,2}$ \\ ${ }^{1}$ France Telecom R\&D division, \\ \{surname.name\}@orange-ft.com \\ ${ }^{2}$ University of Nice Sophia Antipolis \\ FRANCE
}

\begin{abstract}
This paper presents the first step of a research work which aims at predicting the propensity of Professional Virtual Communities (PVC) to create temporary alliances of business. This work is starting from the observation that up to now these business oriented communities lack a conceptual framework for analyzing this issue in a theoretical way. Our approach consists in developing such a conceptual framework using Social Capital as a structuring element. This paper shows how to improve the formalization of PVC by revisiting and using Social Capital concept.
\end{abstract}

\section{INTRODUCTION}

It is often advanced that professional communities acting in industrial sectors could be a way to foster cooperation among firms. The interpersonal relationships developed inside the communities could enable SME to have access to competences for the life-time of a project, competences that they can not afford on a long-time basis. However until now there has been a lack of conceptualization and formalization of the professional communities to establish in theoretical ways in which context they can effectively create or reinforce temporary alliances of business inside clusters of SME called hereafter Virtual Organizations (VO).

Our first assumption is that Social Capital models are relevant for formalizing links between PVC and VO. A lot of similarities in the use of terms actually appear when studying Social Capital, PVC and VO. For instance, professional communities are usually addressed using dimensions such as social norms, social values (trust, and networks) which appear to be constituents of Social Capital; according to Fukuyama [9], "alliances (of business) operate on shared norms and values beyond those necessary for ordinary market transactions." Although Social Capital seems relevant to analyze the concepts of communities, the review of literature achieved so far shows a lack of research investigating professional communities with a Social Capital perspective that validates this assumption. 
Our second assumption is that the communities developing efficient and productive cooperation have a higher propensity to develop VO. Since the Social Capital can be recognized as a stimulating factor for efficient cooperation, this question is still open.

In the long term, our aim is to enhance and use Social Capital theories to predict if certain kinds of PVC have more or less propensity to create VO. The objective of this paper is to improve the formalization of PVC from these theories. It describes the Social Capital conceptual framework that allows us to address this question in a more theoretical way that has been done until now. After this introduction of our fields of investigation, Section 2 of this paper presents the Social Capital conceptual framework that we have designed from a review of Social Capital theories. Section 3 introduces the Professional Virtual Communities baselines and details some key features useful to our perspective. Section 4 presents the summary of the links established between PVC and Social Capital and details the next steps of our research program.

\section{SOCIAL CAPITAL CONCEPTUAL FRAMEWORK}

When studying Social Capital over the last decades, one can notice a shift from developing theories around this concept from a societal perspective (civic commitment which is more or less synonymous with active citizenship, leisure, etc.) to the extension on professional issues, such as networks of professionals and firms. On this topic, social relationships appear to be the main concern of scholars. Therefore, it is commonly agreed that the extent to which an actor has access to resources through Social Capital will depend on three criteria: the actor's connections, the strength of these comnections and all the resources available through these connections. This relates to the noun connectivity which can be defined as the degree to which someone has connections. ${ }^{1}$

Social relationships are mainly addressed by Social Capital theories and connectivity by social network theories. We use as a starting point for our conceptual framework the Nahapiet \& Ghoshal model [16] that has constituted a real breakthrough over the last decades, since it first defines a structured environment of Social Capital with inputs from both Social Capital theories and social network theories. Their model is based on constitutive elements distributed in three key dimensions: Cognitive, Relational and Structural (i.e. network of connections). Their model being focused on the creation of intellectual capital, we will transpose it to the PVC context and enhance it when required with additional works.

The following review of literature on Social Capital enables us to envision our conceptual framework where Social Capital refers to elements of social organization summing up three interrelated dimensions whereas Nahapiet and Goshal [16] see them analytically as distinct dimensions and didn't achieve further developments on their interrelationships. Shared Cognitive dimension and Relational dimension relate to interpersonal relationships (intrinsic and extrinsic behaviours, specific to the

\footnotetext{
'This is different from the definition of connectivity in Information and Communication Technologies (ICT) context, where connectivity is seen more on the propensity of being connected and interconnected than to the fact that exchanges and interactions have already occurred on this connection.
} 
individuals) whereas Structural dimension defines the configuration of the network in terms of connectivity (architecture of the network [20]). Both two first dimensions are going to impact the network's configuration through interactions and collective actions; in return, action feedback will impact them. Cooperation depends on action's efficiency partly determined by the Structural dimension. These interrelations are represented in fig. 1 .

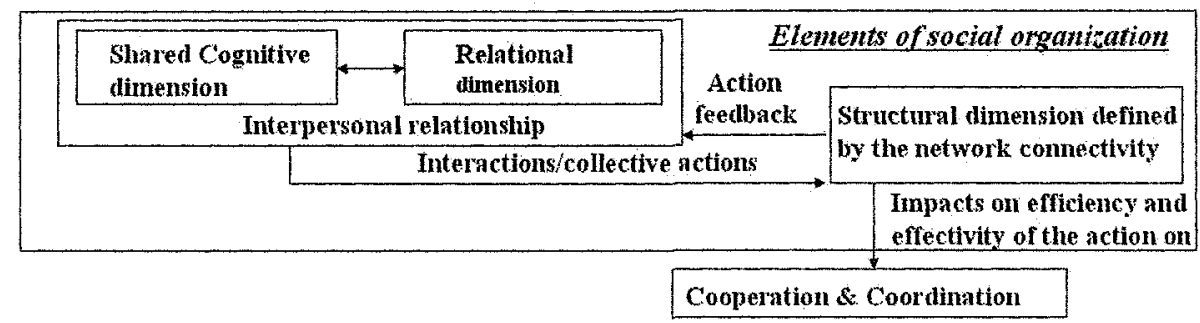

Figure 1: Interrelations of Social Capital dimensions

\subsection{Inputs from Social Capital theories to Cognitive and Relational dimensions}

Several characteristics can be found in the literature to provide a complete overview of Social Capital constituents. First defined by Jane Jacobs [11] as "the result of interpersonal relationships developed over time which create the basis for trust, cooperation and collective actions among communities", Social Capital has been enhanced by Bourdieu [1] with the subsequent features: feelings of gratitude, respect and friendship. Cohen [6] adds to these definitions the ideas of active connections among individuals, mutual understanding and shared values which tie individuals in social networks and communities, then enabling cooperative actions.

Putnam [18] has for his part taken into account "elements of a social organisation such as networks, norms, and values which facilitate coordination and trust for a mutual benefit". Social networks are represented by interconnected groups usually having at least one attribute in common. Social norms are informal rules which govern behaviours: the keystone element being reciprocity. Social values are strongly linked to the issue of trust and can be summed up under the subsequent questions: how can one actor be sure that others will act as they have promised or as they are supposed to, or how can one be sure that they are trustful? Putnam [19] has moreover defined two types of Social Capital: "bridging Social Capital" as bonds of connectedness that are formed across diverse social groups, and "bonding Social Capital" which only cements homogenous groups. This definition is a first step toward the introduction of a structural dimension detailed hereafter.

\subsection{Inputs from Social Network theory to the Structural dimension}

As Social Capital is a multi facet concept, inputs from Social Network Theory about connectivity are of interest for our research work. Social network theory represents networks in terms of nodes (individual actors within the networks) and ties (relationships between the actors). Scholars have divergent visions of the required network topology to create Social Capital: Coleman [7] establishes as sources of Social Capital very dense networks in which each individual is connected and seen by others. With this definition, he introduces the notion of a facilitated development of trust among these closed networks (network closure). Coleman argues that the success of a community is its closure and we can assume that this is certainly due to 
a strong social proximity. On the contrary, Burt $[2,3]$ argues that "the structural hole argument is that Social Capital is created by a network in which people can broker connections between otherwise disconnected segments." His theory advocates for an open and extended network generating creativity, closure of the network being then seen as reductive in terms of innovation.

The concept of weak ties developed by Granovetter [10] is to a large extent also linked to Social Capital development. According to this author, "the argument of Strengthening Weak Ties (SWT) implies that only bridging weak ties are of special value to individuals; the significance of weak ties is that they are far more likely to be bridges than are strong ties. It should follow, then, that the occupational groups making the greatest use of weak ties are those whose weak ties do connect to social circles different from one's own." Social Network theory reinforces the structural dimension as defined by Nahapiet and Goshal [16].

\section{PVC BASELINES}

This paper considers existing communities in a professional context interacting mainly in a virtual way that could develop businesses activities. The IST6 Ecolead Integrated Project ${ }^{2}$ has explored what such communities could be and calls them Professional Virtual Communities (PVC). Ecolead PVC is defined "as an association of "individuals" explicitly pursuing an economic objective identified by a specific knowledge scope. It aims at generating value through members' interaction, sharing and collaboration. This interaction is optimized by the synergic use of ICT-mediated." Until now, few cases studies have analysed the development of business under the form of VO by existing professional communities. The most known cases are in software developments and especially in the Open Source (OS) context. In this section we will characterize the PVC starting from the most widespread types of communities in the professional context and summarize the elements that define or characterize such a community, next we will capture the features that have enabled the development of business oriented activities from existing professional communities in OS context.

\subsection{Professional communities' characteristics}

Above all we need to clarify what kind of communities we are considering and which one we focus on. We are mainly concerned by communities where the virtual and remote coordination is the rule, the geographical regrouping being the exception. These communities are not necessarily restricted to a given firm. Communities established with a business goal, especially PVC, are still a future projection. However, various types of communities can be considered in this context: communities of practice (Cop), epistemic communities, learning communities, communities of interest. In professional context, Cops are probably the most widespread forms of communities and own some features overlapping the epistemic communities; the learning communities can be seen as a rather radical form of Cops whereas communities of interest are virtual places on the Internet where individuals can exchange ideas on a given subject and appear to be further 
from a productive system than Cops and have less legitimacy in a professional context. Consequently we will focus on Cop.

A Cop can be defined as "a group of people who share a concern, a set of problems, or a passion about a topic, and who deepen their knowledge and expertise in this area by interacting on ongoing basis" [21]. It is characterized by the fact that community members have a common purpose, there is a real member participation, the motivation of individual participation is composed of an interest in (individual utility function), and an interest for the social (civic) dimension of a given community, there is a social proximity (geographical versus institutional in virtual Cops) between members, the value of the person is the key element in the system organization. Common purpose can be for instance relative to learning objective or best practices development. It could be seen as a specific case of joint intention that is related to the elaboration of knowledge useful for distributed problems solving. The joint intention has been described in an operational way as a persistent shared goal ${ }^{3}$. Participation covers in fact several concepts. On the one hand it refers to the effective implication of individuals, i.e. the observation of individual actions in collective activities and the evaluation of the cooperativeness and goodwill of the individuals; on the other hand it refers to the network centric positioning of individuals in a set of collective actions. The degree of participation is used as a structural element of the community. Three to four levels of participations linked to expertise levels are considered (kernels, experts, beginners, lurkers). The reference value in Cops is centered on the individual value. It is difficult to model this value as a whole (i.e. not contextual.) Participation and reputation criteria can be used to do it partially. In broad lines, the value of an individual can be perceived as a function of evaluation which has participation as input and reputation as output. Interest in can be seen as the utility function that will determine the interest for a person to invest a collaborative activity corresponding to some expectations: learning, recognition, reciprocity. Interest for refers to the need of an individual related to the collective identification. Let us recall that the prevalence of the individual process of identification to the collective one is rather recent. This identification gives in particular to individuals a set of social values and rules of actions which will make their possible sphere of activities more deterministic, and make the coordination inside the community easier. Social proximity defines a shared space of representations, rules of action and model of thought (ethics). The outline of a given virtual community is thus delimited by institutional proximity in contrast with geographic or organizational proximities.

\subsection{Characteristics that enable Cops to be a system of production}

From an economic point of view, there are two fundamental differences between Cops in a professional context and temporary alliances of business (VO):

- Business alliances are production systems whereas Cops are not -considering that classical understanding of production systems do not see the knowledge creation as a product-; Cops with their learning dimension are closer from consumption systems.

\footnotetext{
${ }^{3}$ For a formalization of several concepts mentioned in this paragraph, in particular collective action, cooperativeness evaluation, joint intention, distributed problem solving, the reader can refer to research done in the Multi-Agents context [8].
} 
- The business temporary alliances are market based types of coordination mechanisms whereas the Cops are not. Let us note that they are not hierarchical based types of coordination any more and as a consequence do not lie within the scope of the usual economic approaches [5, 14].

These two points can be considered in order to determine on which conditions Cop can form VO. The OS context gives us an example of a community that is also a production system that delivers products and that has found a solution (free products) to be compatible with a market based type of coordination. We have identified in OS communities various conditions under which Cop would be able to shift towards a system of production.

- The products achieved (software sources) have a very high level of "standardization", by nature the programming codes are determinist and correspond to a very high level of knowledge exchanges formalization.

- The rules of the community with regard to the commercial spheres are formalized by a social contract (open source licenses).

- The products can be thought and achieved in the distributed modular approach and in addition, this distributed environment can be virtual (all exchanges are mediated by ICT tools). The software production is more and more based on a component approach where each component can be developed separately. The negotiation between the various contributors doesn't necessarily need face to face meetings because the semantic of exchanged knowledge (code programming) doesn't result from a negotiated process.

\section{FINDINGS AND RESEARCH ISSUES}

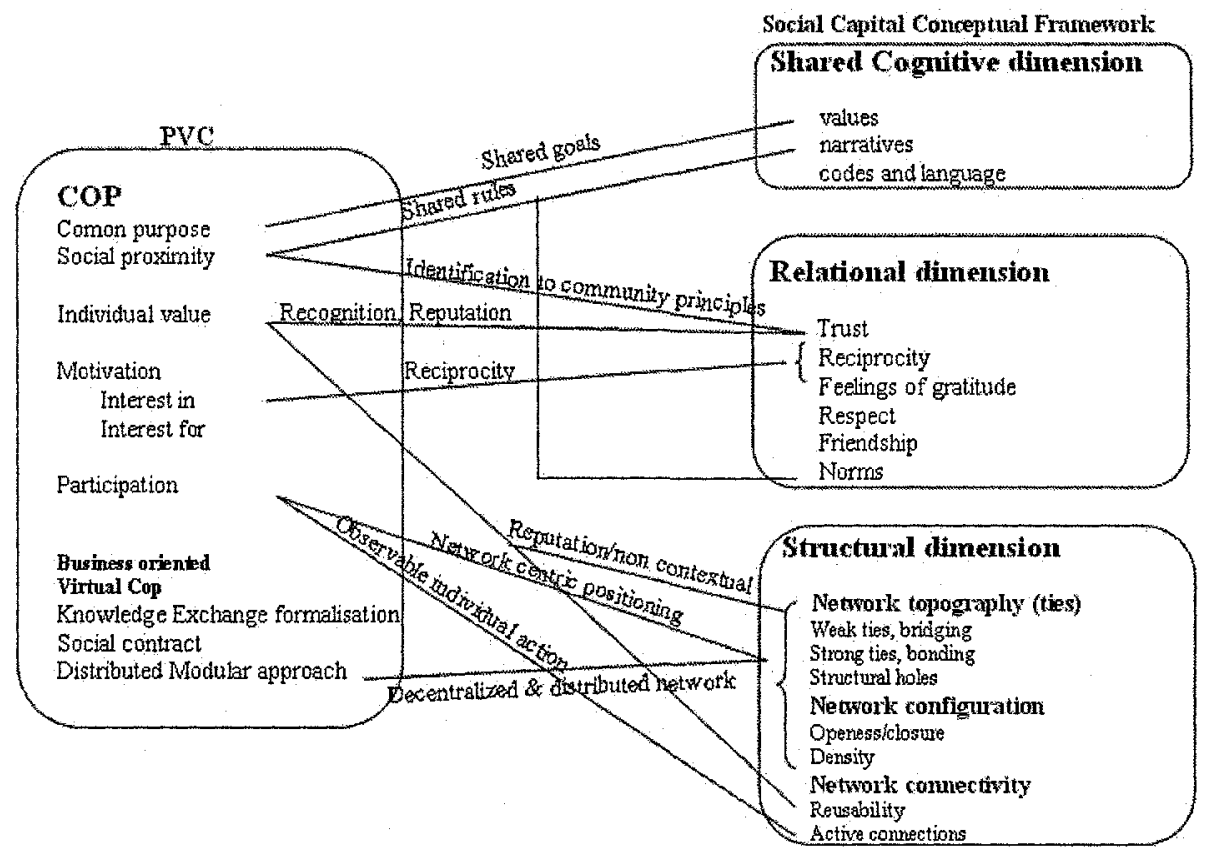

Figure 2: Links between PVC features and Social Capital conceptual framework 


\subsection{Links between PVC and Social Capital elements}

This subsection shows the links between PVC features and the Social Capital conceptual framework elements. It underlines how these links can be used to achieve a questionnaire for an empirical cases based study of PVC in order to assess their Social Capital.

In fig.2, the links are labelled; they join the key features of PVC to the conceptual framework elements. This approach presents the advantages of addressing PVC characteristics in a more theoretical way and of enlarging the way to study them. For instance, "shared goals" links "common purpose" (PVC) to "values" (shared cognitive dimension). Consequently we reuse work developed on shared values by Fukuyama [9] who defines Social Capital "as the existence of a certain set of informal values or norms shared among members of a group that permit cooperation among them." for addressing common purpose issues in Cop and expressing relative questions. "Social proximity" is linked by "shared rules" to (shared) narratives. We will be able to steer our research towards authors such as Orr [17] who explained how shared narratives - soft knowledge that is tacit and difficult to codify - become artefacts (e.g., shared rules) since through them experience becomes reproducible and reusable. "Identification to community principles" links "social proximity" (PVC) and "trust" (Relational dimension) that refers partly to expected behaviours. Research works that we are also leading attempt to design a trust model will be there capitalized [15]. We can reuse, in PVC context, Lin's work [13] for the "recognition, Reputation" label, as his vision of Social Capital represents the "Investment in social relations with expected returns in the marketplace".

For the structural dimension, i.e. all issues in touch with the network, "participation" is one of the relevant PVC features that can be studied with the structural dimension via "Network Centric position" and "Observable individual action" links. [4] defines closeness of the two partners as key to the degree of tacit knowledge transfer. This analysis is a result based on Knowledge Management background.

\subsection{Future works}

We have identified elements which are missing in the Social Capital framework to improve and perfect the PVC characteristics modelling. Then, there is a need to add a distinction between individual and collective actions and a need to address the distributed dimensions. For these two points, Multi-agent formalization will be used to complete the conceptual framework [8].

With this framework, we explore to what point Social Capital allows us to differentiate more or less productive PVC especially in terms of innovative creations, efficient coordination and successful cooperation. This propensity to have productive cooperation is intrinsic to VO. We are currently addressing cooperation and coordination in VO context by combining three main dimensions: Proximity (geographical, technological and organisational), Degree of formalization of Cooperation or Coordination and frequency of Interactions [12]. The formalization of VO will be improved in using and completing, if necessary, the Social Capital conceptual framework presented in this paper. Once the set of formalizations is ended, we will be able to establish transitivity links between PVC and VO and be able to provide assumptions to the propensity of certain kinds of PVC to form a VO. 
We will next validate the assumptions based on this theoretical work via an empirical study on different kinds of Professional Communities: intra/inter organisation communities such as (virtual) COP and inter firm communities such as PVC. Findings of this empirical study on real communities will give us accurate inputs on professional communities and their ability to form temporary alliances of firms or professionals. In a later step and depending on the results of this empirical validation, our research target is to work out a first set of functionalities for an ICT tool in the context of PVC creating VO.

\section{REFERENCES}

1. Bourdieu, P, "The Forms of Capital ", in J. G. Richardson (dir.), Handbook of Theory and Research for the Sociology of Education, New York, Greenwood Press. 1986

2. Burt R.S. "Structural Holes versus Network Closure as Social Capital" in Social Capital: Theory and Research edited by Nan Lin, Karen S.Cook, and R.S. Burt. A. de Gruyter, 2001

3. Burt R.S. "Structural holes and Good Ideas" pre-print of an article to appear in the American Journal of Sociology 2003

4. Cavusgil, S.T., Calantone, R.J., Zhao, Y. "Tacit knowledge transfer and firm innovation capability ", in Journal of Business \& Industrial Marketing, 18 (1), 6-2 2003

5. Coase $\mathrm{R}$ "The nature of the firm" Economica 1937

6. Cohen, D., \& Prusak, L. "In good company: How Social Capital makes organizations work." Massachusetts: Harvard Business School Press. 2001

7. Coleman, J. S. "Social Capital in the creation of human capital." American Journal of Sociology, 94, 95-120.1988

8. Ferber J"Multi-Agent systems" Addison-Wesley 1999

9. Fukuyama, F. "The Great Distuption: Human nature and the reconstitution of social order", Profile Books, London 2000

10. Granovetter "The strength of weak ties: a network theory revisited" presented as a paper at the Conference on Contributions of Network Analysis to Structural Sociology, Albany, N.Y., April 4, 1981.

11. Jacobs, J. "The death and life of great American cities." NJ: Penguin Books. 1965

12. Ladame S, Crave S "Le concept de "Proximité" comme élément structurant et favorisant des coopérations dans des modes organisationnels réticulaires et modulaires." Cinquièmes journées de la proximité June 06 Bordeaux

13. Lin N "Building a network theory of Social Capital" Connections 22(1):28-51, INSNA 1999

14. Malone $\mathrm{T} W$ "Modeling coordination in organizations and markets" Management Science volume $33 \mathrm{n}^{\circ} 101987$

15. Melaye D, Demazeau Y, Bouron T, "Which Adequate Trust Model for Trust Networks?" 3rd IFIP Conference on Artificial Intelligence Applications and Innovations (AIAI), June 2006

16. Nahapiet J, S. Ghoshal "Social Capital, Intellectual Capital, and the Organizational Advantage" in The strategic Management of Intellectual capital and organizational knowledge - Oxford University Press

17. Orr J. "Sharing Knowledge Celebrating Identity: War Stories and Community Memory in a Service Culture." In Middleton D. S. and Edwards D. (Eds) Collective Remembering: Memory in Society. Beverley Hills CA: Sage Publication 1990

18. Putnam, R.D. "The prosperous Community", The American Prospect vol.4 n'13 1993

19. Putnam, R.D. "Bowling alone: America's declining Social Capital." journal of Democracy, 6 , 65-78 1995

20. Thomas C, Barlatier P-J "Solution TIC et développement de capacités réseau : le rôle du processus de codification dans l'expérimentation KMP." AIMS, XVème Conférence Internationale de Management Stratégique juin 2006. 2006

21. E. Wenger, R. McDermott, and W. Snyder "Cultivating Communities of Practice." Harvard business School Press 2002 